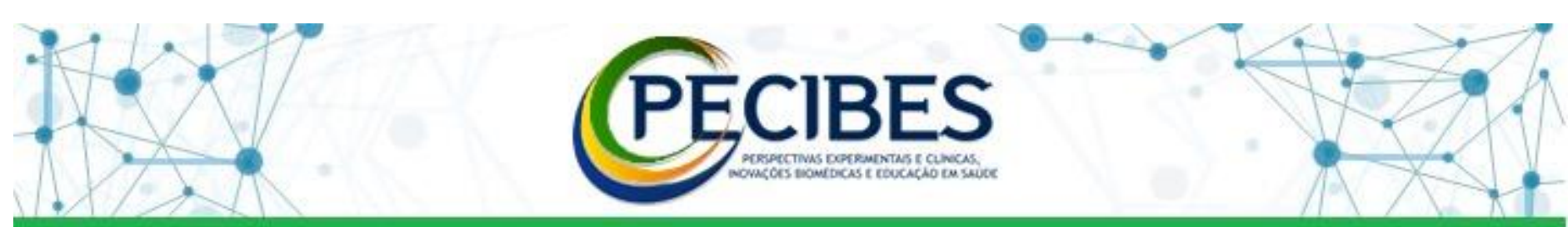

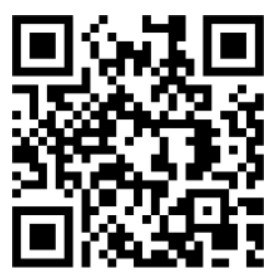

http://www.seer.ufms.br/inde x.php/pecibes/index

\footnotetext{
*Autor correspondente: Dayane Aparecida Moisés Caetano Bottini, Universidade Federal de Mato

Grosso do Sul UFMS.E-mail do autor: daay-

caetano@hotmail.com
}

Descritores: Assoalho Pélvico. Climatério. Modalidades de tratamento incontinência.

Key words: Pelvic Floor. Climacteric Treatment Modalities. Urinary incontinence. Sexuality.

\section{Efeito do treinamento muscular do assoalho pélvico (TMAP) versus ginástica abdominal hipopressiva (GAH) na função sexual de mulheres climatéricas: ensaio clínico randomizado}

Effect of pelvic floor muscle training (TMAP) versus hypopressive abdominal gymnastics (GAH) on urinary symptoms in climacteric women: a randomized clinical trial

Marina Martins Barbosa Moraes ${ }^{1}$; Diego Vargas da Silva ${ }^{1}$; Dayane Aparecida Moisés ${ }^{2}$; Adélia Lúcio ${ }^{4}$; Rui Malta da Silva Filho ${ }^{4}$; Ana Beatriz Gomes de Souza Pegorare ${ }^{5}$

1. Graduando do curso de Fisioterapia da Universidade Federal de Mato Grosso do Sul. Campo Grande, MS, Brasil.

2. Fisioterapeuta. Mestranda do Programa de Pós-graduação em Ciências do Movimento da Universidade Federal de Mato Grosso do Sul - UFMS, Campo Grande, MS, Brasil.

3. $\mathrm{PhD}$, Fisioterapeuta do Ambulatório de Ginecologia do Hospital Universitário Maria Aparecida Pedrossian, Empresa Brasileira de Serviços Hospitalares (HUMAP/EBSERH) UFMS, Campo Grande, MS.

4. Médico do Ambulatório de Ginecologia do Hospital Universitário Maria Aparecida Pedrossian, Empresa Brasileira de Serviços Hospitalares (HUMAP/EBSERH) UFMS, Campo Grande, MS, Brasil.

5. PhD, Docente do Programa de Pós-graduação em Ciências do Movimento da Universidade Federal de Mato Grosso do Sul - UFMS, Campo Grande, MS, Brasil.

RESUMO - A sexualidade e a continência são aspectos centrais da qualidade de vida e podem ter impactos negativos no climatério. Atualmente são disponíveis novos métodos que buscam melhorara vida nessa fase. Objetivo: Comparar o impacto da Ginástica Abdominal Hipopressiva (GAH) versus o treinamento convencional dos músculos do assoalho pélvico (TMAP) sobre a função sexual de mulheres no período de climatério. Métodos: Ensaio clínico, realizado na Clinica Escola Integrada (CEI-UFMS), aprovado pelo Comitê de Ética em Pesquisa Número do Parecer: 7846614.2.0000.0021. As mulheres envolvidas no estudo serão divididas aleatoriamente em dois grupos: G1: treinamento convencional dos músculos assoalho pélvico (TMAP) e G2: método ginástica abdominal hipopressiva (GAH). Ambos os grupos foram submetidas ao protocolo de exercícios por 26 sessões, 2 vezes por semana. A avaliação é realizada pré e pós tratamento, consiste na aplicação do Índice de Função Sexual Feminina (FSFI). Resultados parciais: Até o momento temos 16 participantes do G1 tratadas e 10 participantes do G2, com idade média 53,35 (4,09SD). Os resultados preliminares apontam para melhora significativa no Score global da função sexual do grupo G1 (média inicial= 20,3 +-7,87 SD versus final=23,75 + $7,99 \mathrm{SD}$ ) em relação ao grupo G2 (média inicial=18,77 - 10,50SD e final=18,3 +-11,54SD). Conclusão: Os resultados preliminares apontam que o TMAP proporciona maior benefício do que a GAH sobre a função sexual feminina. 